\title{
Escuta Clínica, Triagem e Plantão Psicológico em um Serviço-Escola Pernambucano
}

\author{
Shirley Macêdo ${ }^{1}$ \\ 1Universidade Federal do \\ Vale do São Francisco, PE, Brasil.
}

\author{
Ana Lícia Pessoa Nunes ${ }^{1}$ \\ 1Universidade Federal do \\ Vale do São Francisco, PE, Brasil.
}

Milena Vitor Gama Duarte ${ }^{1}$

1Universidade Federal do Vale do São Francisco, PE, Brasil.

Resumo: Esta pesquisa teve como objetivo geral compreender experiências de escuta clínica nas modalidades de triagem e plantão psicológico entre estudantes lotados em um serviçoescola de Pernambuco. Os objetivos específicos foram descrever sentidos dessas experiências, investigar como eles percebiam a formação recebida para ofertarem esses serviços, como também identificar dificuldades enfrentadas nos processos e estratégias utilizadas para dirimi-las. Utilizouse o método da hermenêutica colaborativa, e 18 colaboradores, subdivididos em quatro grupos de discussão, responderam a uma entrevista aberta com pergunta disparadora. Os resultados foram analisados em uma perspectiva fenomenológica, revelando que os estudantes enfrentavam dificuldades como desarticulação entre teoria e prática, manejo do tempo, angústia e insegurança inicial, além de falta de suporte estrutural recebido pelo serviço-escola para ofertar tais serviços. No entanto era possível a eles desenvolver a escuta, deixando-a fluir na condução dos processos em direção às demandas dos clientes. Diante de estratégias como capacitação ofertada pelo serviço-escola, suporte emocional recebido pelas equipes de supervisão e seus próprios processos pessoais, conseguiam enfrentar as dificuldades encontradas durante a formação, sentindo-se, apesar de tudo, valorizados e reconhecidos pelo serviço prestado. Concluiu-se, principalmente, a importância de inserir estudantes em serviços-escola em práticas anteriormente ao estágio obrigatório e em diversas modalidades de porta de entrada, desde que tais estratégias estejam integradas ao projeto pedagógico do curso, cabendo à instituição oferecer uma formação que, efetivamente, articule teoria e prática nas experiências cotidianas do estudante no processo de vivenciar e aprimorar sua escuta clínica ao tornar-se psicólogo.

Palavras-chave: Escuta Clínica, Pesquisa Fenomenológica, Formação do Psicólogo, Triagem, Plantão Psicológico.

\section{Clinical Listening, Screening and Psychological Support on a School Clinic in Pernambuco}

\begin{abstract}
This research aims to understand experiences of clinical listening in the modalities of screening and psychological support among students at a school clinic in the state of Pernambuco, Brazil. With that, the study sought to describe the feelings arising from these experiences, investigating how students perceived the adequacy of the academic education to offer these services and identifying hardships faced in the processes, as well as strategies adopted for solving them. Using the collaborative hermeneutics method, 18 collaborators were subdivided into four discussion groups and submitted to an open interview with a triggering question. The results were analyzed in a phenomenological perspective, revealing that students experienced
\end{abstract}


difficulties regarding disarticulation between theory and practice, time management, anguish, insecurity, and lack of structural support received from the school to offer such services. Despite these factors, the students managed to develop clinical listening skills, letting it flow according to patients' demands. The training offered by the school service, the emotional support received by supervisory teams, and their own personal processes enabled students to face the problems encountered during their formation, feeling valued and recognized for the service provided. The results denote the importance of promoting practices of clinical listening among students at school clinics before they attend the mandatory internship, provided that such strategies are integrated to the pedagogical project. Thus, the institution must offer a formation that effectively integrate theory and practice, improving students' process of clinical listening.

Keywords: Clinical Listening, Phenomenological Research, Psychologist Training, Screening, Psychological Support.

\title{
Escucha Clínica en Clasificación y Turno Psicológico en un Servicio Escuela Pernambucano
}

\begin{abstract}
Resumen: Esta investigación tuvo como objetivo general comprender experiencias de escucha clínica en las modalidades de clasificación y turno psicológico entre estudiantes de un servicio escolar en Pernambuco. Los objetivos específicos fueron desde exponer el sentido de estas experiencias, investigar cómo percibían la formación para ofrecer esos servicios, así como identificar las dificultades encontradas y estrategias para solucionarlas. Utilizándose el método de la hermenéutica colaborativa y 18 colaboradores, subdivididos en cuatro grupos de discusión, contestaron a una entrevista abierta con una pregunta desencadenante. Se analizaron los resultados de una perspectiva fenomenológica, revelando que enfrentaron dificultades como desarticulación entre teoría y práctica, manejo del tiempo, angustia e inseguridad inicial, además de la falta de soporte estructural recibido por la escuela. Sin embargo, les fue posible desarrollar la escucha, dejándola fluir en los procesos clínicos según la demanda del cliente. Se utilizó estrategias como capacitación ofrecida por la escuela, soporte emocional por la supervisión y sus procesos personales propios, lograron enfrentar las dificultades encontradas durante la formación; sintiéndose, a pesar de todo, valorados y reconocidos por el servicio realizado. Se concluyó, principalmente, en la importancia de añadir a los estudiantes en los servicios escolares con prácticas anteriores a las obligatorias y en varias modalidades de integración, siempre que esas estrategias se incorporen en el proyecto pedagógico del curso, correspondiendo a la institución ofrecer una formación que articule efectivamente la teoría y práctica en las experiencias diarias del alumno en el proceso de experimentar y mejorar su escucha clínica al convertirse en psicólogo.
\end{abstract}

Palabras clave: Escucha Clínica, Investigación Fenomenológica, Formación del Psicólogo, Clasificación, Turno Psicológico.

\section{Introdução}

Mesmo que diversas pesquisas venham sendo realizadas no Brasil sobre competências em estagiários, estágios e supervisão em Psicologia (Amaral et al., 2012), Pernambuco parece ser um estado em que não se investe significativamente na produção de conhecimento sobre experiências em serviços escola de Psicologia. Reconhecendo, portanto, a importância dessas instituições na formação de futuros psicólogos (Löhr \& Silvares, 2006), investigou-se o tema escuta clínica, contextualizando-o na prática de estudantes de Psicologia lotados em um serviço-escola 
pernambucano e transitando por diversos saberes e fazeres (Krug \& Boeckel, 2016).

A escuta clínica é um tema contemporâneo para aqueles que se ocupam da formação do psicólogo. Entendida como essencial ao fazer psicológico (Braga, Daltro, \& Danon, 2012), não é uma escuta comum (Barbosa, Laurenti \& Silva, 2013), mas uma competência atrelada ao cuidado (Dourado, Quirino, Lima \& Macêdo, 2016). Sendo uma estratégia de intervenção terapêutica, torna-se necessário o desenvolvimento de habilidades para o processo de escuta eficaz, não só na Psicologia (Velasco, Rivas \& Guazina, 2012), mas em outras profissões de saúde (Mesquita \& Carvalho, 2014).

A escuta clínica pode minimizar angústias, diminuir o sofrimento e ampliar autorreflexões do paciente (Mesquita \& Carvalho, 2014), mas é um grande desafio para o estudante de Psicologia escutar clinicamente (Dourado, Macêdo, \& Lima, 2016; Dourado, Quirino, Lima, \& Macêdo, 2016). A escuta qualificada é uma prática que singulariza o estudante em seu compromisso ético e social com o usuário (Velasco et al., 2012). Os autores até aqui citados alertam que, apesar da relevância do tema, há carência de estudos sobre seu valor para a efetividade do trabalho de profissionais de saúde e propõem capacitações para o ensino promissor desta competência.

A escuta qualificada e comprometida implica ouvir o outro, valorizando sua dimensão subjetiva, sendo necessário ao ouvinte se comprometer com a produção da autonomia desse outro em relação ao seu processo de saúde-doença. É uma escuta que permite o desenvolvimento de uma postura clínica que invoca o atravessamento de diferentes saberes, favorecendo, a quem cuida, humanizar o atendimento ao facilitar a responsabilização desse outro sobre seu próprio cuidado, pois todos os envolvidos são protagonistas da intervenção a ser realizada (Velasco et al., 2012).

Para dar conta dos múltiplos sentidos do processo de quem demanda ajuda psicológica, um psicólogo, ao ouvir o outro, tece e destece sentidos (Feijoo, 2010). Precisa desenvolver qualidades pessoais e profissionais, como: acolhimento caloroso e humano, cuidado, respeito, empatia, coerência interna, dar feedback e ter capacidade de relacionamento interpessoal (Sousa, 2017). Certamente que a formação acadêmica desse profissional será fundamental para aquisição dessas qualidades e para o exercício profícuo da profissão, cuja formação é regulamentada por dispositivos legais e institucionais (Krug \& Boeckel, 2016).
Um desses dispositivos é a Resolução no 8 , de 7 de maio de 2004, que instituiu as Diretrizes Curriculares Nacionais (DCN) para os cursos de graduação em Psicologia, revogada pela Resolução no 5 , de 15 de março de 2011, pelo Conselho Nacional de Educação (CNE). Em 2018, o Conselho Federal de Psicologia (CFP), a Associação Brasileira de Ensino de Psicologia e a Federação Nacional dos Psicólogos promoveram um amplo debate nacional aberto com professores, coordenadores de cursos e de serviços escola, estagiários e supervisores, visando construir coletivamente uma revisão dessas diretrizes para garantir uma formação presencial de qualidade, contemplar novas práticas e resguardar os direitos humanos. A minuta foi aprovada pelo Parecer Técnico no $346 / 2018$, do Conselho Nacional de Saúde, por meio da Resolução $\mathrm{n}^{\circ}$ 597, de 13 de setembro de 2018 (Conselho Federal de Psicologia [CFP], 2018). No entanto continuam valendo ainda as DCN de 2011, pois o Ministério da Educação ainda não a aprovou.

Nessas DCN, são elencadas competências a ser desenvolvidas, tais como: diagnosticar; avaliar e atuar em problemas humanos de ordem cognitiva, comportamental e afetiva; manejar processos grupais; ofertar aconselhamento psicológico e psicoterapia. Também são apresentadas habilidades para dar suporte às competências, a exemplo de descrever, analisar e interpretar manifestações verbais e não verbais para acessar estados subjetivos. Neste estudo, defende-se que essas competências e habilidades estão relacionadas com a escuta clínica.

Para além dessas diretrizes, as práticas sobre as quais os estudantes se debruçam, transitórias entre a formação acadêmica e o exercício da profissão, são reguladas pelo CFP, que elaborou a Carta de Serviços sobre Estágios e Serviços Escola (CFP, 2013), orientando as atividades supervisionadas, ficando a aprendizagem profissional e sociocultural da (o) graduando sob a responsabilidade e coordenação da instituição de ensino superior (IES). Nesse sentido, as atividades práticas nos serviços-escola são base para a construção da identidade profissional, sendo necessário que as IES invistam em condições reais de capacitação profissional.

Um serviço-escola deve propiciar o desenvolvimento de competências alicerçadas nos objetivos do curso e nas ênfases curriculares oferecidas, é um importante instrumento na consolidação dos projetos pedagógicos dos cursos e tem como finalidade atender à necessidade de formação, favorecendo 
ao estudante aplicar na prática as teorias e técnicas psicológicas aprendidas em sala de aula, desempenhando um papel social significativo na atenção psicológica à comunidade. Assim, sua função básica é habilitar estudantes em práticas psicológicas de acordo com as demandas da sociedade e atender com qualidade essas demandas (Ancona-Lopez, 2005; Boeckel et al., 2009; Löhr \& Silvares, 2006; Melo-Silva, Santos, \& Simon, 2005).

Dentre as práticas, diversas modalidades têm sido ofertadas à comunidade. Algumas dessas são consideradas serviços de porta de entrada porque o ingresso dos clientes nessas instituições se dá a partir delas (Amaral et al., 2012; Rocha, 2011; Sá, Azevedo, \& Leite, 2010), a exemplo da triagem de orientação à queixa escolar (Freller et al., 2001), do plantão psicológico (Schmidt, 2004), do psicodiagnóstico colaborativo (Yehia, 2004), do acolhimento (Teixeira \& Vorcaro, 2009), da triagem (Rocha, 2011), do psicodiagnóstico interventivo (Evangelista, 2016) etc. Por serem mais frequentemente debatidos em congressos sobre serviços escolas de Psicologia, eventos que ocorrem anualmente no Brasil há vários anos (Krug \& Boeckel, 2016), nos quais se questionam a formação do psicólogo e se propõem melhorias para serviços de porta de entrada, optou-se nesta pesquisa por focar os serviços de triagem e plantão psicológico.

A triagem destina-se a selecionar quem pode ser atendido, considerando a especificidade da demanda e as modalidades de atendimentos disponíveis. Não se trata necessariamente de psicodiagnóstico, mesmo que objetive conhecer a pessoa que busca ajuda, avaliar sua situação e sugerir encaminhamento mais adequado (Cavalheiro et al., 2012; Krug, Boeckel, \& Andrade, 2016; Rocha, 2011).

De acordo com Rocha (2011), existe a triagem tradicional (TT) e a triagem estendida ou interventiva (TI). A primeira é bastante difundida entre profissionais da Psicologia, mais conhecida por psicólogos e usuários dos serviços de saúde. Constitui uma estratégia que cumpre três objetivos principais: coletar dados pessoais do cliente, identificar sua queixa e realizar um breve diagnóstico. Para realizá-la, um estagiário pode utilizar testes psicológicos, entrevistas, questionários e anamnese. A escuta deve ser ampla, compreendendo o sujeito inserido no mundo sociocultural-econômico (Krug et al., 2016).

Já a segunda constitui-se como espaço de cuidado e visa recepcionar o cliente escutando-o para aquilo que ele tem a dizer e o que o mobilizou a procurar ajuda psicológica. Não é um mero processo de seleção de demanda ou coleta de dados da história do cliente, mas "parte da intervenção propriamente dita, [pois] há uma clarificação da situação psicodinâmica individual ou grupal, e isso tem efeito psicoterapêutico" (Rocha, 2011, p. 127). Assim, na TI, que pode ser individual ou grupal, a ajuda pode se encerrar na própria triagem, configurando um processo psicodiagnóstico que tem início, meio e fim, e que pode durar entre quatro a seis sessões (Herzberg \& Chammas, 2009).

As intervenções em grupo, resultantes da flexibilização do contexto clínico, têm sido fonte de pesquisas, cujos objetos de estudo são as próprias relações grupais e o modo como aí se processa a escuta do sofrimento psíquico e a expressão da subjetividade, atentando para o fazer prático e ético da clínica em Psicologia (Nery \& Costa, 2008). Pensa-se que essas ideias podem ser estendidas para estudos sobre TI grupal, visto a necessidade de encaminhamentos mais efetivos para modalidades de atendimento mais compatíveis com as demandas da clientela e o planejamento de ações em prol da saúde e dos direitos de acesso a ela (Cavalheiro et al., 2012). Inclusive, a TI grupal pode favorecer, entre outros, o enfrentamento pelos serviços escola de Psicologia de dois grandes problemas: as longas listas de espera e a evasão dos clientes. Isso porque, além de agrupar pessoas em uma sessão, essas, ao serem chamadas, percebem como positiva a efetividade do serviço e desenvolvem um vínculo maior com a instituição, principalmente quando o serviço-escola pode oferecer os chamados grupos de espera (Guerrelhas \& Silvares, 2000).

O plantão psicológico (PP), muitas vezes adotado como alternativa para a triagem, mas diferentemente desta, não tem finalidade de encaminhamento imediato nem de adequação da demanda aos serviços oferecidos (Schmidt, 2004). Sendo reconhecido pelo CFP (Freire, 2004), é um dispositivo viável e pertinente à prevenção e promoção da saúde (Gonçalves, Farinha, \& Goto, 2016). Surgiu no Instituto de Psicologia da Universidade de São Paulo (USP), por volta de 1960 (Rosenthal, 1999), e tomou vulto no Brasil a partir dos anos 1990, diante do processo de reestruturação das instituições de assistência pública de saúde no país, o que exigiu do psicólogo um novo olhar e atuação que garantissem à população o exercício da cidadania e o efetivo direito de acesso à saúde (Souza, Barros Neta, \&Vieira, 2012). Além disso, essa modalidade clínica de 
atendimento atende às necessidades do homem contemporâneo e às situações de crise que este enfrenta no cotidiano social, que é, para esse sujeito, um exercício penoso de sobrevivência diante das ameaças a sua saúde mental (Furigo et al., 2008; Gomes, 2012; Mahfoud, 2004).

O PP é definido como intervenção emergencial ou urgente que acolhe a pessoa no exato momento de sua necessidade, sem marcação prévia (Gonçalves et al., 2016); e atenção psicológica em forma de pronto atendimento, que permite que maiores camadas da população possam ser atendidas, preventivamente, constituindo uma alternativa eficaz à diminuição das longas filas de espera por psicoterapias (Furigo et al., 2008; Gomes, 2012). O objetivo é acolher e ajudar a pessoa a lidar com seus limites e recursos, mas o estagiário, ao enfrentar o inesperado e escutar alguém emergencialmente, pode lidar com conflitos internos quando se identifica com histórias e angústias vivenciadas pelo cliente (Chaves \& Henriques, 2008).

No PP, o acolhimento e a escuta do plantonista estão pautados na sua crença na capacidade do sujeito para enfrentar e superar suas próprias crises, e resolver conflitos psicológicos urgentes. Por vir se consolidando como atenção psicológica fundamental diante das demandas do sujeito contemporâneo, a prática de PP pode viabilizar ao estagiário o desenvolvimento de competências para atuação profissional mais efetiva (Furigo et al., 2008).

A escuta, nesta modalidade clínica, consiste em uma abertura à compreensão dos mal-estares em relações sociais contextualizadas, possibilitando ressignificações de experiências. O estagiário acompanha o outro na expressão do vivido, disponibilizando-se para que modos de sentir, pensar e agir sejam manifestados e, eventualmente, o outro possa se apropriar dos sentidos de seu existir no mundo (Braga, Mosqueira, \& Morato, 2012). Assim, ele facilita que esse outro lide com dificuldades e busque em si mesmo os recursos de que precisa para sair da situação limitante que enfrenta (Gonçalves et al., 2016).

Portanto, as atividades de triagem e PP representam, também para os estudantes de Psicologia, portas de entrada para um período de intensa capacitação, exploração e descoberta do mundo profissional do psicólogo. São atividades desafiadoras, que colocam os estudantes diante do desconforto do inesperado, da insegurança diante de limitados preceitos teóricos internalizados, da necessidade de apropriação crítica da formação e das experiências que serão pontos de partida para desenvolver a atitude clínica (Sá, Azevedo, \& Leite, 2010).

Diante do exposto, poder investigar a experiência de estudantes nas modalidades clínicas aqui referendadas significa, além de compreender sua formação acadêmica, atentar para as bases da identidade profissional de futuros psicoterapeutas (Barbosa et al., 2013). Assim, o objetivo geral desta pesquisa foi compreender experiências de escuta clínica nas modalidades de triagem e plantão psicológico entre estudantes lotados em um serviço-escola de Pernambuco. Os objetivos específicos foram descrever sentidos dessas experiências, investigar como eles percebiam a formação recebida para ofertarem esses serviços, como também identificar dificuldades enfrentadas nos processos e estratégias utilizadas para dirimi-las.

\section{Método}

$\mathrm{O}$ estudo se fundamentou na abordagem qualitativa fenomenológica, pela qual o conhecimento é construído de acordo com as realidades subjetivas próprias de sujeitos socialmente inseridos, sendo foco do pesquisador o sentido e os significados de experiências humanas para indivíduos que a vivenciam (Holanda, 2006). Nesse sentido, adotou-se o método fenomenológico denominado hermenêutica colaborativa (Macêdo, 2015), por meio do qual o pesquisador busca promover grupos de discussão para favorecer que colaboradores se engajem em um diálogo e, encarnados que estão no mundo, compartilhem experiências, resgatem suas histórias, defendam suas opiniões e contestem as de outros (Laville \& Dionne, 1999; Macêdo \& Caldas, 2013), podendo o pesquisador observar processos de consenso e divergência (Turato, 2003) na produção conjunta de novos sentidos.

No contexto dialógico promovido, a confiança genuína, estando presente entre os membros do grupo, permite o respeito pelas descrições e histórias de cada um e o eclodir de um fundamento de coesão, emergindo daí o comprometimento comum quando o diálogo caminha e se expande. Para a realização do estudo, defende-se, tal como propõe Turato (2003), a investigação do sujeito em seu lugar de pertencimento e atuação. Assim, os colaboradores desta pesquisa foram 18 estudantes de Psicologia lotados em um serviço-escola de Pernambuco.

O estudo atendeu aos preceitos éticos de pesquisas com seres humanos contidos na Resolução no 466 de 
2012, está registrado no CAAE no 69091017.0.0000.5196, e a coleta apenas teve início após aprovação pelo Comitê de Ética em Pesquisa da Universidade Federal do Vale do São Francisco (Univasf), sob o Parecer no 2.170.493.

Para a condução da pesquisa, os estudantes foram convidados em reuniões semestrais que normalmente eram promovidas pelo serviço-escola em meados de semestres letivos. Apenas participaram aqueles que prestavam serviços há pelo menos dois meses e se disponibilizaram a colaborar de forma voluntária. Foram formados pela equipe de pesquisa, portanto, quatro grupos de acordo com a modalidade investigada e a disponibilidade de horários dos colaboradores: um com quatro estagiários que realizavam triagem tradicional (TT); um com cinco estudantes extensionistas que realizavam triagem interventiva (TI); um com cinco e outro com quatro estagiários que ofereciam plantão psicológico (PP1 e PP2).

Os grupos de discussão foram promovidos a partir de uma pergunta disparadora e registrados em gravador digital. Cada grupo durou cerca de uma hora e meia e foi conduzido por bolsistas de iniciação científica, aqui denominados facilitadores, em sala previamente agendada no próprio serviço-escola. A pergunta disparadora (Amatuzzi, 2009) é uma interrogação que permite ao sujeito contatar e descrever suas experiências, assim como favorece que o pesquisador tente alcançar o sentido destas. Tendo a função de abrir o diálogo, tal pergunta viabiliza um desencadear da narrativa da experiência detalhada com enfoque em acontecimentos e ações (Jovchelovitche \& Bauer, 2001; Macêdo, 2015). No entanto o entrevistador deve ficar atento ao fenômeno que emerge e inserir outras perguntas ao longo do diálogo para atender aos objetivos específicos da pesquisa. A pergunta disparadora proferida foi "Como você descreve sua experiência de escuta ao participar de triagem individual (ou triagem interventiva em grupo ou plantão psicológico) no serviço-escola?".

O procedimento de análise das entrevistas esteve embasado nos passos propostos por Amatuzzi (2009) e Macêdo (2015). No entanto, como uma pesquisa fenomenológica se faz ao caminhar, conduziu-se o processo de análise percorrendo-se os seguintes passos: a) os conteúdos gravados nos grupos de discussão eram transcritos na íntegra pelos bolsistas entrevistadores, mas cada membro da equipe de pesquisa escutava a gravação de cada grupo e lia a transcrição quantas vezes fossem necessárias para descrever os elementos significativos da experiência do diálogo compartilhado entre facilitadores e colaboradores, inserindo comentários sobre os significados que percebiam no texto da transcrição, usando o editor de texto Word for Windows; b) a equipe de pesquisa se reunia e cada membro lia seus comentários, negociando divergências para chegar a um consenso de como se registrariam os elementos significativos da experiência, mas sempre retornando ao conteúdo da entrevista grupal para perceber se algo tinha escapado à compreensão coletiva; c) após alguns encontros, a equipe concluía a análise coletiva preliminar sobre o que percebia do que estava sendo compartilhado pelos colaboradores de determinado grupo de discussão, ao que chamou de presentificação dos sentidos das experiências compartilhadas; d) o texto produzido dessa análise preliminar era encaminhado por e-mail a cada colaborador integrante de um referido grupo, a fim de que ele revisasse o texto, pudesse acrescentar novos elementos e/ou realizasse modificações na análise do grupo que participou (nenhum colaborador realizou mudanças no conteúdo do texto); e) após essas devolutivas, a equipe de pesquisa, novamente reunida, procedeu à descrição final das Unidades de Sentido da experiência investigada, com base nas descrições em comum contidas em todos os grupos.

Vale destacar que, devido aos facilitadores serem estudantes do mesmo curso que os colaboradores, a metodologia da pesquisa esteve ancorada em um resgate histórico que prevê que, por meio da conversação, se contestem tradições para que os envolvidos, ao contra-argumentarem, cheguem a um novo olhar sobre seu caminhar (Macêdo, 2015). Essa característica do método da hermenêutica colaborativa favoreceu que os facilitadores compartilhassem sentidos na conversa para tentar alcançar a experiência investigada.

Como forma de manter o sigilo quanto à identidade dos colaboradores, eles foram nomeados por pseudônimos referentes a sementes típicas do sertão nordestino, já que essas simbolizam, para a equipe de pesquisa, a possibilidade de, na aridez da existência, brotar e florir diante de dificuldades. A seguir, na análise e discussão dos resultados, serão destacadas em negrito as unidades de sentido, favorecendo que o leitor compreenda a experiência investigada.

\section{Resultados e discussão}

Para melhor compreensão dos resultados, apresentam-se informações sobre o curso, seu projeto 
pedagógico e o serviço-escola em questão. Tais informações foram obtidas por meio de depoimentos dos próprios estudantes e enriquecidas por conteúdos constantes no site da instituição e na página do serviço-escola.

O curso funcionava em uma universidade federal. Seu projeto pedagógico, respeitando as DCN de 2011, previa que, em cinco anos, o estudante tivesse uma formação generalista que contemplasse os principais enfoques teórico-metodológicos da Psicologia contemporânea. Buscava formar profissionais capazes de integrar teoria, prática e realidade social, como aspectos importantes na construção do conhecimento e na atuação profissional. Para tanto, perspectivava que desde o início do curso houvesse disciplinas com bom embasamento teórico e experiências práticas, tendo o estudante possibilidade de formação em até duas ênfases. Apesar dos estágios básicos serem oferecidos em um contexto de práticas integrativas a partir do quarto semestre do curso, o estágio obrigatório, realizado geralmente em uma das três abordagens estudadas até o oitavo semestre e em uma das diversas áreas em que os supervisores atuavam, era cursado no último ano. Nesse momento, a maioria dos estudantes (mesmo os que não tiveram experiência em pesquisa e extensão), tinha seu ingresso efetivo em práticas supervisionadas, sendo priorizado por muitos deles estagiar no serviço-escola da instituição.

No serviço-escola também atuavam alguns poucos estudantes em projetos de extensão e pesquisa, independentemente de semestre cursado. Os supervisores também eram docentes e havia psicólogas que davam suporte permanente às atividades práticas dos estudantes. Para compreender o funcionamento e o fluxograma de prestação de serviços, o estudante inicialmente passava por uma capacitação, cujos temas eram as diversas modalidades clínicas ofertadas, questões relacionadas à saúde mental, aspectos legais da formação do psicólogo em serviço-escola, possibilidades de parceria com Rede de Atenção Psicossocial (Raps) da região, preenchimento de prontuários, atuação com crianças, adolescentes e seus responsáveis.

As portas de entrada do cliente no serviço-escola na época da pesquisa eram a triagem tradicional (TT), a triagem interventiva (TI) grupal e o plantão psicológico (PP). A TT era realizada ao longo de toda a semana, por todos os estagiários, que atendiam individualmente cada cliente que havia preenchido uma ficha cadastral e cujo nome era registrado na lista de espera. No primeiro atendimento, que durava uma hora, o estagiário deveria preencher o formulário de triagem para ser anexado ao prontuário do cliente. $\mathrm{O}$ formulário continha espaços para informações sobre dados sociais e demográficos, queixa, demanda, detalhes sobre o atendimento realizado, o uso ou não de medicações e possíveis encaminhamentos. Para tanto, os estagiários recebiam instruções das psicólogas do serviço-escola, mas quem fazia a supervisão da triagem era o supervisor de cada um.

A TI era realizada em grupo, também com clientes cadastrados em espera, podia levar até oito encontros de duas horas, não prescrevia formulário, mas o estudante fazia diários de bordo de cada sessão, descrevendo a evolução da demanda ao longo dos atendimentos. Correspondia a um projeto de extensão de uma docente, que implantou o serviço visando diminuir a fila de espera da instituição e supervisionava, em um encontro semanal, oito alunos que cursavam entre o quinto e o oitavo semestre para a atividade que era conduzida em dupla.

Já o PP, também um projeto de extensão, tinha dois formatos. Um era realizado em uma tarde da semana com um supervisor presente para orientar os plantonistas. Os clientes buscavam ajuda naquele dia e aguardavam na sala de espera. Era definido o máximo de 15 clientes por tarde (cadastrados ou não, já contemplados por atendimentos ou não), não previa tempo de encerramento da sessão, a não ser o limite do horário de fechamento do serviço-escola. $\mathrm{O}$ outro formato era ofertado para casos emergenciais que surgissem ao longo da semana, sem agendamento prévio e sem a presença direta do supervisor, mas com o suporte das psicólogas do serviço. Nos dois formatos, os estagiários atendiam em dupla e alguns não realizavam o estágio exclusivamente no serviço-escola, mas na Raps da região; um cliente não era atendido duas vezes pela mesma dupla; e quatro docentes experientes na prática e na pesquisa em PP se revezavam na supervisão.

No que concerne aos grupos de discussão pesquisados, a primeira Unidade de Sentido a se destacar é a desarticulação teoria-prática na formação. Os colaboradores relataram que a formação no curso, com uma grande quantidade de carga horária teórica, não era suficiente para eles realizarem os atendimentos. Diante disso, todos percebiam a importância da semana de capacitação oferecida pelo serviço-escola, mas alguns não se sentiam capacitados para atuar na 
modalidade investigada de maneira mais específica, alegando que a capacitação do serviço-escola era muito generalizada.

Eu não acho que exista uma formação. Pelo menos eu não consegui perceber uma formação específica para triagem, mas sim de todo um manejo com os clientes e tudo mais, com a situação. . . Mas, na verdade, no sentido burocrático mesmo, do serviço em si, da documentação que tem que assinar, como tem que se posicionar (Jatobá, TT).

Considerando-se o debate atual em torno das DCN (CFP, 2018) e a finalidade de um serviço-escola ofertar serviços de qualidade na direção das diversas demandas da sociedade (Krug \& Boeckel, 2016), reconhece-se, aqui, a urgência de programas de capacitação em modalidades específicas nessa instituição, tanto ao longo da graduação quanto do estágio obrigatório, fortalecendo-a em seu papel de preparação de pessoas qualificadas para futura atuação profissional, já que há um projeto pedagógico que prevê uma formação de qualidade. A partir de tal afirmação, pode-se falar, por exemplo, naquilo já pontuado por Kuczynski (2014) quanto a não haver uma estrutura de saúde preparada em serviços de emergência e de saúde mental no que concerne a lidar com o suicídio infanto-juvenil, que é crescente. Os estudantes entrevistados também pareciam perceber ter adquirido poucos conhecimentos teóricos e práticos para atuar diante de comportamento suicida, necessitando de capacitação para atender essa e outras demandas sociais que surgiam nos serviços de porta de entrada. Veja-se, por exemplo, o que relatou Beladona (PP2):

Um sujeito prestes a se suicidar, por exemplo, a gente pode pensar que ele está muito mais urgente que alguém que vem com ansiedade por ter reprovado numa disciplina, e a gente recebe essa salada mista de casos e acaba atendendo tudo como se fosse uma coisa só.

Apesar dos entraves, os colaboradores entraram em consenso nos grupos de discussão quanto à validade da semana de capacitação oferecida como um avanço no serviço-escola, já que contemplava aspectos que não foram ensinados em sala de aula. Juá (PP1) relatou: "a semana de formação foi uma glória, porque não dá. ... Eu acho que vim umas duas vezes, então, muito rápido. Eu conhecia o espaço, mas não conhecia como funcionava. Essa semana de formação proporcionou esse conhecimento". Já Agilim (TI) disse:

Tem a semana de formação para os estagiários que a gente participa. ... Você vê várias oficinas em vários momentos . . para conhecer a rede, que é muito importante, para ter conhecimento do encaminhamento - "quem vem de onde?". E essa da rede foi muito importante, porque eu vi pouco na minha graduação [e] não foi suficiente para a prática.

A partir desses recortes de narrativas, pôde-se questionar o que vinha sendo aprendido em sala de aula durante a formação por esses estudantes para, efetivamente, conseguirem articular teoria e prática nas suas atividades no serviço-escola, já que o projeto pedagógico do curso indicava buscar integrar teoria, prática e realidade social. Santos e Nóbrega (2017) já alertavam que o estágio deveria proporcionar ao estudante ter um contato inicial com o exercício da profissão, diminuindo o distanciamento entre o campo e a sala de aula, congruente com a proposta das DCN. Porém foram Ribeiro e Araújo (2017) que constataram que a proposta de articular e aplicar as práticas pedagógicas que são ensinadas não é efetivada, o que resulta do distanciamento que há entre teoria e prática durante o curso.

Outra unidade de sentido compartilhada foi o fluir da escuta na condução dos processos. No grupo TT, a ficha era percebida como direcionadora, de modo que alguns estagiários atuavam mais com uma escuta investigativa durante o atendimento, limitando-se ao roteiro que precisavam seguir na condução da triagem. Como relatou Catingueira (TT), "a ficha de triagem é um guia, é tanto que ela é generalista para quase todo mundo, com exceção de um grupo ou outro. ... Se a pessoa não traz nada, você sabe qual protocolo seguir". No entanto outros contestaram e pareciam perceber que a escuta variava, mas, ao disponibilizá-la para identificar a demanda, sentiam angústia e dificuldades: "é muito difícil você só ouvir e você tem que perceber alguma coisa. No começo, principalmente, achar que é uma coisa tão simples, quando na verdade não é, e, às vezes, isso também te angustia" (Jatobá, TT).

As estudantes que realizavam TI, por sua vez, relataram ter clareza de que não era um momento apenas de coleta de informações, mas uma experiência 
de troca que proporcionava um melhor desenvolvimento da escuta, considerando que essa modalidade de triagem ocorria em grupo e havia um tempo maior para realizarem o procedimento, o que requeria delas disponibilidade para serem mediadoras e habilidades para manejar o processo. Agilim referiu: " a triagem interventiva é um processo mais contínuo, mais completo. . . Você acompanha a evolução dos clientes/ usuários e consegue desenvolver melhor a escuta, em minha opinião, do que se fosse uma triagem pontual.

A partir desse recorte de fala, pode-se refletir sobre o quanto uma postura mais investigativa, explicativa ou tecnicista em uma triagem, assim como o uso de fichas e formulários durante o atendimento, pode dificultar a escuta nesse processo, considerando que, como foi destacado anteriormente, alguns estagiários que realizavam TT se sentiam direcionados por esses recursos, colocando em foco mais o conteúdo que deveria ser transcrito que a demanda do cliente. Chamou atenção dos facilitadores alguns estagiários fazerem TT mecanicamente e se preocuparem tão somente em cumprir um protocolo: “a gente enxerga a triagem só como uma fonte de informações mesmo, uma coleta para poder encaminhar o sujeito" (Imburana, TT). No entanto outros contestavam, percebendo a limitação do formulário, indicando disponibilidade para escutar para além dele e intervir:

Às vezes, a gente chega meio que fechado só naquela ficha que está ali, mas a gente tem que estar aberto a escutar mesmo, embora seja só um encontro, porque o cliente, às vezes, coloca lá na ficha certa queixa, mas vem com outra muito ampla, que você tem que intervir e até exigir do próprio cliente que você intervenha, e você não pode simplesmente estar fechada naquela triagem, naquela anamnese inicial (Pereiro, TT).

Vale ressaltar que, na capacitação do serviço-escola, eles não eram orientados a não intervir na TT, mas esclarecidos da necessidade de preenchimento adequado da ficha de triagem. Ao contrário, no processo de TI investigado, os estudantes não precisavam seguir nenhum modelo de formulário inicial e tinham, inclusive, mais sessões para identificar a demanda. Além disso, os estudantes que realizavam essa modalidade pareciam perceber que o desenvolvimento da escuta psicológica dependia tanto da orientação recebida para a importância dessa disponibilidade na atuação quanto da própria abertura para ouvir e estar inteiro, o que era difícil e levava um tempo para ser experienciado:

Você entende que a função do psicólogo é escutar. Mas você não entende a dimensão dessa escuta, $e$ quando você vai para o campo é que você vai ver, $e$ é muito difícil! . . É muito complicado você estar ali inteiro para ele! E é algo que eu percebo que estou começando a desenvolver, ter essa disponibilidade maior (Umbu, TI).

Nos grupos de PP, os estagiários também relataram que a disponibilidade e abertura no aqui e agora eram básicos, mesmo quando não estavam bem ou cansados, já que era o próprio cliente quem direcionava, fazia fluir e dava rumo ao atendimento:

Tem gente que já chega muito, muito, muito mobilizada, e aí você fica naquela de: "e agora?" Às vezes, não precisa fazer muita coisa, muitas intervenções, ofato de a pessoa estar falando já vai fazendo com que ela, ali mesmo, já vá ouvindo e se articulando, se orientando. ... Ela vai se situando um pouco mais (Caroá, PP2).

A condução do PP pelos estagiários, nesse sentido, está coerente com o que propõem autores sobre essa modalidade clínica, a exemplo de Rocha (2011) que, ao diferenciar TT, TI e PP, ressalta que nos dois últimos não se segue um roteiro preestabelecido, mas o curso da experiência do cliente, protagonista de seu próprio cuidado.

Outro aspecto que parece ser significativo no fluir da escuta é os atendimentos em dupla de PP e TI. A observação do que o colega faz, a sintonia de pensamentos ou mesmo quando um deles indica está se identificando com a história do cliente e o outro percebe o movimento leva o atendimento em dupla a ser sentido como um recurso estratégico:

Essa questão da dupla também é muito interessante. Às vezes, rola uma sintonia muito legal, você está... pensando em uma pontuação que vai fazer, e aí seu colega do lado vai e pergunta, ou fala algo que você estava pensando. Esses momentos me deixaram bem contentes, porque eu estou indo no mesmo pensamento que ele, assim, do colega, então deve ser esse o caminho (Xiquexique, PP1). 
Interessante no recorte de fala acima é que Xiquexique era estagiária do nono semestre do curso e seu colega era concluinte, com um pouco mais de experiência nos atendimentos de PP. Compreende-se, portanto, que a sintonia entre eles e a intervenção do colega podem oferecer mais segurança e funcionar como uma confirmação do potencial de escuta clínica pela iniciante, dando-lhe mais segurança.

Essa segurança sentida por estagiários iniciantes também foi relatada por colaboradores da pesquisa de Nunes e Morato (2020), que constataram a importância do atendimento em dupla, salientando, no entanto, a necessidade do acolhimento do membro mais experiente em relação ao iniciante e a dificuldade que é a realização do trabalho em conjunto em um atendimento de PP.

Outra unidade de sentido foi dificuldades no manejo do tempo, seja porque alguns clientes chegavam mobilizados e falavam por mais tempo, seja porque os colaboradores sentiam necessidade de fazer algo em relação a como o sujeito iria sair do encontro. Quando clientes chegavam mais mobilizados, alguns estagiários de TT, por exemplo, alegaram se sentir convocados a realizar intervenções e pontuações, saindo do âmbito investigativo, por considerarem que era um momento importante para a permanência do sujeito no processo, promovendo acolhimento inicial. Catingueira (TT) revelou:

Tem uma coisa aqui que é importante: a gente deixar a pessoa falar para você não oferecer uma escuta punitiva para ela naquele momento. Porque, às vezes, é o primeiro contato dela com qualquer serviço, então em um primeiro momento você deixa ela se expressar. Às vezes, ela tem dificuldade de falar sobre um determinado assunto, se vocênão falar, ela pode não falar nunca mais, nem aqui no lugar, porque em outro lugar ela já nem fala.

Devido à necessidade de, na maioria das vezes, haver esse acolhimento inicial, alguns estagiários compararam TT com PP. Entretanto é importante lembrar que eles eram esclarecidos na capacitação recebida no serviço-escola e pelos supervisores da diferença dos objetivos dessas modalidades. Aprender a diferenciá-las ao mesmo tempo em que as praticavam, no entanto, parecia gerar conflito nos estagiários, principalmente os iniciantes, que, além de ansiosos por acertar (Aguirre et al., 2000), enfrentavam, em modalidades como PP, situações inesperadas em que sentiam com maior impacto o limite de uma formação teórica diante de uma prática desafiadora de ofertar cuidado sem tender a diagnosticar a partir de um crivo de análise preestabelecido, como bem enfatizam Chaves e Henriques (2008).

Além disso, segundo os colaboradores, alguns clientes, por desconhecerem as especificidades das práticas psicológicas, chegavam aos atendimentos esperando procedimentos equivocados ou mesmo acreditando que apenas um psicólogo poderia resolver seus problemas. Nesses casos, os colaboradores assumiam a responsabilidade de, no tempo do atendimento, explicar o trabalho do psicólogo e as diferenças das modalidades. Essa estratégia pareceu poder facilitar aos estudantes atingir o objetivo da modalidade ofertada, mesmo que o cliente já tivesse se submetido a outro atendimento no próprio serviço-escola:

Por isso, também, que eu acho importante explicar como é a modalidade, porque, às vezes, têm pessoas que, por exemplo, vieram do plantão, que é uma modalidade totalmente diferente da triagem, aí chega na triagem . . . querendo uma intervenção como se fosse no plantão, e aí a gente é bom explicar que não é, que na triagem a proposta geralmente não é essa, é mais de encaminhar (Pereiro, TT).

Compreende-se, portanto, a efetividade dessa estratégia dos colaboradores dessa pesquisa, considerando-se o já proposto por Botomé (2010), que compete ao profissional psicólogo responsabilidade de esclarecer, ensinar e divulgar o que é Psicologia ou o que os psicólogos fazem, identificando medidas de melhoria para a vida das pessoas.

O tempo que alguns clientes levavam para falar também foi uma dificuldade apontada pelos colaboradores de TI na condução de grupos, principalmente quanto à distribuição do tempo de fala entre os integrantes, bem como o manejo do tempo para que o atendimento fosse "proveitoso", considerando o limite da sessão:

Mas o fator do tempo é o que mais pesa para mim! Principalmente quando tem uma pessoa que fala muito no grupo e as outras pessoas, muitas vezes, não têm a oportunidade de falar. ... Eu fico agoniada! Sem saber manejar, direcionar a fala para as outras pessoas. É muito difícil na hora você cor- 
tar a fala do sujeito e puxar para outra coisa, principalmente jogar para o grupo (Angico, TI).

Nesse aspecto vale lembrar que, de acordo com o projeto pedagógico do curso, os alunos cursavam, no quinto semestre, uma disciplina de processos grupais, com carga horária teórica e prática. Considerando-se que os estudantes que atuavam em TI cursavam ou já haviam cursado a disciplina, pode-se questionar como vinham aprendendo a manejar certos entraves na condução de grupos.

Os colaboradores narraram, também, sobre a importância do tempo para a disponibilidade e o tempo para intervir, acreditando necessitarem ser sensíveis para o momento, considerando que não poderiam prever o que aconteceria, que era o próprio cliente que trilhava o caminho e que cada um tinha seu tempo. Frisaram, principalmente no PP, que as intervenções dependiam desse caminhar, diferentemente do atendimento contínuo, em um processo psicoterapêutico. Para eles, seria preciso ser sensível à relação no aqui e agora para sentir o momento de intervir, porque, se esse momento passasse, não conseguiriam resgatar. Aqui vale ressaltar o já referido anteriormente e discorrido por Chaves e Henriques (2008), sobre como estagiários plantonistas lidam com o inesperado e reconhecem a necessidade de acompanhar o modo como cada cliente se encaminha no processo. Veja-se:

Quando você faz um atendimento individual, mas é contínuo, você tem um plano terapêutico, né?... No atendimento emergencial não, qualquer coisa pode acontecer. Você não tem como seguir um caminho linear, para ter um início, meio e final de processo terapêutico. É o próprio cliente que vai trilhar esse caminho, que vai dizer se é o final do atendimento ou se não é. É ele que diz, não é o tempo que acaba (Alecrim, PP2).

Além disso, os estagiários revelaram uma preocupação com a maneira como o cliente iria sair do atendimento, sendo necessária a sensibilidade do estudante para perceber várias questões. Narraram buscar algumas estratégias quando percebiam a mobilização do cliente, como forma de melhor acolher. Agilim (TI) relatou: "teve uma demanda muito complicada e eu sabia que se deixasse [a cliente] muito mobilizada, eu não encerraria. Eu iria atrás do funcionário perguntar se tinha outra sala disponível, se eu podia estender o tempo".
Diante disso, pode-se destacar também como unidade de sentido, a angústia e insegurança inicial dos estudantes diante das mobilização de clientes durante os atendimentos ou mesmo no momento em que eram convocados a atender em situações de urgência, algo revelado com maior destaque por estudantes que realizavam PP, embora os que atuavam em TT e TI também tenham mencionado. Os estagiários de PP relataram que a não possibilidade de programar algo previamente para o encontro, por não saberem $o$ que estaria por vir, gerava insegurança, o que poderia levá-los a duvidar da própria capacidade:

Acho que é mais nos primeiros mesmo, que a gente tem aquela angústia de "meu Deus, eu não sei o que eu vou fazer!". Eu não conheço essa pessoa, eu não sei nada, como ela se comporta em momento de atendimento.... A gente não tem mesmo como pensar no que vai fazer até o momento em que a gente chega lá e faz (Alecrim, PP2).

Enquanto Pereiro (TT) disse "a gente começa um pouco nervoso, né? Como é que vai ser? Se a gente vai dar conta do que aparecer", Angico (TI) retoma a questão do excesso de teorias aprendidas e a dificuldade da pouca experiência prática:

Eu compartilho do que Trapiá falou da segurança, porque, no começo, eu estava muito, muito insegura. Por quê? Por nunca ter participado de nada parecido. A gente está só no curso com muita teoria, teoria, teoria e, quando chega à prática, aí você diz: “Sim, vou fazer o que agora?” (Angico, TI).

Paparelli e Nogueira-Martins (2007) também constataram insegurança nos sujeitos participantes de sua pesquisa quanto à atuação em PP. As autoras alegaram que isso se deve a características da própria modalidade, já que o encontro com o sujeito ocorre apenas uma vez. Para os plantonistas desta pesquisa, a insegurança também se dava porque o encontro era único e inesperado, e, mesmo que o cliente pudesse retornar outras vezes, "cada semana é um caso novo que se pega” (Juá, PP1), pois não se atendia a mesma pessoa duas vezes.

Pode-se refletir acerca do assunto, contudo, que, sendo o PP uma modalidade que se dispõe a acolher a urgência/emergência, énecessário pensar outros modos de auxiliar estagiários a lidarem com ou amenizarem a 
angústia inicial que sentem, já que planejar o que quer que seja acaba por descaracterizar a própria modalidade. Uma forma de favorecer mais experiências seria inserir estudantes já em semestres iniciais do curso, a exemplo do que Nunes e Morato (2020) indicam que ocorre no Instituto de Psicologia da USP.

A falta de suporte estrutural recebido para ofertar o serviço foi outra unidade de sentido compreendida. Segundo os colaboradores, o espaço físico do serviço-escola não foi estruturado para absorver o aumento de demandas. Relataram que não havia isolamento de som, a quantidade de salas era insuficiente, a acessibilidade era inadequada, as salas eram desconfortáveis e inapropriadas, o que dificultava um melhor acolhimento à situação de emergência, pelo tempo delongado do atendimento. Mandacaru (PP1) revelou: "[o serviço] não tem dado conta, muito pela estrutura física mesmo. Quem fez não pensou em futuro, não pensou em ampliação".

Os colaboradores também falaram sobre dificuldade de articulação entre o serviço-escola, outros serviços de saúde e a Raps da região. Afirmaram que não havia uma comunicação efetiva com a rede do Sistema Único de Saúde (SUS), o que levava o serviço-escola a absorver todas as demandas, acabando por se sobrecarregar, conforme revela Alecrim (PP1): "eu percebo muita dificuldade do serviço de se comunicar com outras instituições de saúde... Dificilmente a gente faz um encaminhamento ou a gente recebe um encaminhamento de outros lugares".

Com relação a essa dificuldade, é válido lembrar o estudo de Gomes e Dimenstein (2016) sobre a experiência de um serviço-escola do Rio Grande do Norte, onde a articulação entre as redes do Sistema Único de Assistência Social (Suas) e do SUS, apesar de existir, ainda era frágil e informal, já que parte dos encaminhamentos era realizada apenas verbalmente. Romagnoli, Amorim, Severo e Nóbrega (2017) também analisaram as dificuldades da intersetorialidade em saúde mental no Nordeste, constatando o mesmo.

Alguns colaboradores também enfatizaram que as psicólogas do serviço-escola necessitavam de formação quanto às modalidades de atendimento existentes no serviço, a fim de, na capacitação oferecida, dar melhor suporte às necessidades deles ao longo do dia a dia. Coité (PP1) relatou: "está faltando uma melhor qualificação de quem já está dentro".

Enquanto sentem falta de suporte estrutural, outros colaboradores revelaram como significativa a presença de suporte emocional recebido para ofertar $o$ serviço. A maioria referiu momentos de conversa informal após os atendimentos e encontros externos ao serviço-escola com os colegas, o que levava ao estabelecimento de diálogos e brincadeiras cotidianas, sendo estes elementos considerados por eles como estratégias para lidar com a ansiedade. Babosa (PP2) relatou: "meio que a gente se ajuda aqui... supre isso. A gente vê que a pessoa sai mobilizada do atendimento, pesada. Então vamos conversar, até onde se pode conversar a respeito do que foi feito lá dentro".

No entanto alguns dos colaboradores percebiam que o cuidado era restrito aos grupos de supervisão, e não do serviço-escola: "o espaço de cuidado, que não é do aluno com os alunos, é a supervisão. ... As estratégias [de cuidado] que a gente tem disponíveis dificilmente são do serviço. A única, que é aqui no serviço, é a supervisão" (Umari, PP1). Interessante que Umari não participava cotidianamente do serviço-escola e revelou não realizar psicoterapia. Considerando o suporte emocional reconhecido entre outros colegas estagiários e a existência de psicólogas no serviço para assessorar as atividades deles, vale refletir o que essa estagiária concebia como espaço de cuidado, atentando-se para o já alertado por Oliveira-Monteiro e Nunes (2008) de que a atuação dos supervisores pode ser confundida pelo estagiário a de um psicoterapeuta.

Em muitos casos, os colaboradores optavam pelo autocuidado em uma psicoterapia pessoal como revelado por Mandacaru (PP1): "uma coisa que me ajudou, fundamental, foi a terapia, que é um autocuidado que eu pago a um preço acessível, que me foi possível por ter um desconto por ser estagiária". Revelou isso ao informar que alguns de seus colegas buscavam serviços de profissionais recém-formados pela universidade, que, por conhecerem sua situação, os atendiam a baixo custo. Interessante perceber, aqui, que alguns estudantes e estagiários sustentavam sua atuação pelo tripé destacado por Aguirre et al. (2000) para a atitude clínica - processo pessoal, estudo e supervisão -, o que poderia auxiliá-los na compreensão dos processos psíquicos dos clientes.

Talvez esse tripé explique outra unidade de sentido encontrada: valorização e reconhecimento do serviço realizado, que muitos colaboradores revelaram sentir. Quanto a isso, a supervisão era percebida como um espaço de aprendizagem que transmitia segurança e suporte aos estudantes, tanto pela possibilidade de ouvir e intervir sobre as experiências compartilhadas 
pelos colegas quanto pelos estudos realizados nesses grupos e pelo feedback que recebiam do(a) supervisor(a) sobre os atendimentos que faziam. Trapiá (TI) destacou: "Você acha que não vai dar conta quando está inserida em um grupo ou no atendimento de triagem interventiva individual. Só que, pela segurança que elas [supervisoras] passam, a gente consegue dar conta. Pelo menos eu consigo".

Por fim, compreendeu-se o sentido que o cliente tinha para o estudante como fonte de valorização e reconhecimento, pois destacaram que, em alguns momentos, era possível constatar imediatamente os resultados: "você pode observar esse progresso da pessoa durante o atendimento. ... Muitas vezes, a pessoa chega chorando, ou em um momento de muito desespero, e sai sorrindo, dizendo que está melhor" (Babosa, PP1). Ressaltaram, ainda, que o fato de alguns clientes, por vezes, não falarem nada no momento nos encontros, não significava que eles não estivessem implicados nos processos e que esses não eram transformadores, pois nas entrevistas devolutivas chegavam a revelar "que a vida mudou completamente! [que] podia não estar falando nada, mas estava escutando tudo" (Umbu, TI). A percepção desse feedback dos clientes pode favorecer, inclusive, o processo de construção de identidade profissional do estagiário, algo já defendido por Mazer e Melo-Silva (2010).

\section{Considerações finais}

Diante dos resultados até aqui expostos, considera-se que os objetivos dessa pesquisa foram alcançados. Pelas informações complementares, percebeu-se que o projeto do curso buscava responder às exigências das DCN e que o serviço-escola ofertava possibilidades de formação prática. No entanto parece que os estudantes ainda sentiam falta de uma formação que atendesse às suas necessidades acadêmicas e idealizações profissionais. Compreende-se, portanto, que os colaboradores do estudo pareciam experienciar a escuta clínica nas modalidades de triagem e plantão psicológico enfrentando dificuldades que os tiravam da fantasia de uma formação ideal; e que o serviço-escola, mesmo sendo um lugar de tensões, insatisfações e conflitos, era o espaço onde eles podiam, finalmente, fortalecer a base para a construção de uma identidade profissional.
Foi possível compreender, também, que a abertura à experiência e a disponibilidade para caminhar na direção da demanda do cliente levavam alguns estudantes a irem além de uma simples coleta de dados na TT e, mesmo que a realizassem a partir de um formulário que os guiava, alguns disponibilizavam aos clientes uma escuta mais atenta, percebida por eles como pertinente a uma TI ou ao PP.

Além disso, compreendeu-se que, para dirimir dificuldades como insegurança inicial no estágio obrigatório no último ano, inserir estudantes em práticas nos serviços-escola em semestres mais iniciais do curso parece ser uma estratégia interessante para desenvolver a escuta clínica quando a formação em Psicologia, apesar da institucionalização de quase dez anos das DCN, ainda se baseia em um currículo predominantemente teórico.

Nas práticas em serviços-escola, contudo, reconhece-se, a partir deste estudo, a importância de estudantes atuarem em diversas modalidades de porta de entrada, visto que se compreendeu que as experiências de escuta pareciam ser diferenciadas dependendo de cada processo (da objetividade de um formulário à sensibilidade e abertura ao inusitado).

Essas estratégias, contudo, devem estar integradas ao projeto pedagógico do curso, cabendo à instituição oferecer uma formação que, efetivamente, articule teoria e prática nas experiências cotidianas do estudante no processo de vivenciar e aprimorar sua escuta clínica ao tornar-se psicólogo.

Diante de uma pesquisa que focou apenas estudantes lotados em um serviço-escola pernambucano, considerando a carência de investigações em outros serviços-escola do Nordeste, sugere-se, como possibilidade de novos estudos, que se incluam como colaboradores profissionais da equipe técnica que também atuam nessas instituições. Também se sugerem pesquisas sobre a condução de serviços de porta de entrada dependendo da abordagem teórico-prática adotada no estágio. Além dessas, seriam interessantes estudos longitudinais, ao longo do período de estágio, para se compreender a escuta clínica de estudantes, visando uma melhor compreensão da articulação entre diferentes práticas com o projeto pedagógico do curso. 


\section{Referências}

Aguirre, A. M. B., Herzberg, E., Pinto, E. B., Becker, E., Carmo, H. M. S., \& Santiago, M. D. E. (2000). A formação da atitude clínica no estagiário de psicologia. Psicologia USP, 11(1), 49-62. https://doi.org/10.1590/ S0103-65642000000100004

Amaral, A. E. V., Luca, L., Rodrigues, T. D., Leite, C. A., Lopes, F. L., \& Silva, M. A. (2012). Serviços de psicologia em clínicas-escola: Revisão da literatura. Boletim de Psicologia, LXII(136), 37-52.

Amatuzzi, M. M. (2009). Psicologia fenomenológica: Uma aproximação teórica humanista. Estudos de Psicologia (Campinas), 26(1), 93-100. https://doi.org/10.1590/S0103-166X2009000100010

Ancona-Lopez, M. (2005). Considerações sobre as diretrizes curriculares nacionais para os cursos de psicologia. In L. L. Melo-Silva, M. A. Santos, \& C. P. Simon (Orgs.), Formação em psicologia: Serviços-escola em debate (pp. 83-116). Vetor.

Barbosa, F. D., Laurenti, M. A., \& Silva, M. M. (2013). Significados do estágio em psicologia clínica: Percepções do aluno. Encontro: Revista de Psicologia, 16(25), 31-53.

Boeckel, M. G., Krug, J. S., Lahm, C. R., Ritter, F., Fontoura, L. O., \& Sohne, L. C. (2009). O papel do serviço-escola na consolidação do projeto pedagógico do curso de psicologia. Psicologia: Ensino \& Formação, 1(1), 41-51.

Botomé, S. P. (2010). A quem nós, psicólogos, servimos de fato? In O. H. Yamamoto, \& A. L. Costa (Orgs.), Escritos sobre a profissão de psicólogo no Brasil (pp. 169-203). EDUFRN.

Braga, A. A. N. M., Daltro, M. R., \& Danon, C. A. F. (2012). A escuta clínica: Um instrumento de intervenção do psicólogo em diferentes contextos. Revista Psicologia, Diversidade e Saúde, 1(1), 87-100.

Braga, T. B. M., Mosqueira, S. M., \& Morato, H. T. P. (2012). Cartografia clínica em plantão psicológico: Investigação interventiva num projeto de atenção psicológica em distrito policial. Temas em Psicologia, 20(2), 555-569.

Chaves, P. B., \& Henriques, W. M. (2008). Plantão psicológico: De frente com o inesperado. Psicologia Argumento, 26(53), 151-157.

Cavalheiro, N. C., Garcia, B. C., Iwata, H., Pace, J., Jr., Rosa, H. R., Valente, M. L. L. C., \& Migliorini, W. J. M. (2012). Triagem interventiva: A caracterização de uma demanda. Revista SBPH, 15(2), 3-16.

Conselho Federal de Psicologia. (2013). Carta de serviços sobre estágios e serviços-escola. http://site.cfp.org.br/ wp-content/uploads/2013/09/carta-de-servicos-sobre-estagios-e-servicos-escola12.09-2.pdf

Conselho Federal de Psicologia. (2018). CNS aprova minuta das novas diretrizes curriculares da Psicologia. https://site.cfp.org.br/cns-aprova-minuta-das-novas-diretrizes-curriculares-da-psicologia/

Dourado, A. M., Macêdo, S., \& Lima, D. (2016). Experienciando a escuta clínica no estágio em psicologia: um estudo fenomenológico. In A. A. S. Sampaio, \& D. H. P. Espíndula (Orgs.), Pesquisa e prática em psicologia no sertão (pp. 471495). Instituto Walden 4. https://www.walden4.com.br/livrosw4/pdf/iw4_sampaio_espindula_1e_2016.pdf

Dourado, A. M., Quirino, C. A., Lima, M. B. A., \& Macêdo, S. (2016). Experiências de estudantes de psicologia em oficinas de desenvolvimento da escuta. Phenomenological Studies: Revista da Abordagem Gestáltica, 22(2), 209-218.

Evangelista, P. (2016). O psicodiagnóstico interventivo fenomenológico-existencial grupal como possibilidade de ação clínica do psicólogo. Revista da Abordagem Gestáltica, 22(2), 219-224.

Feijoo, A. M. L. C. (2010). A escuta e a fala em psicoterapia: Uma proposta fenomenológico-existencial. Ifen.

Freire, P. S. G. L. (2004). Pronto atendimento psicológico em um serviço universitário: Compreendendo processos sob o olhar da psicologia analítica [Dissertação de mestrado]. Pontifícia Universidade Católica de Campinas.

Freller, C.C., Souza, B. P., Angelucci, C. B., Bonadio, A. N., Dias, A.C., Lins, F. R. S., \& Macêdo, T.E. C. R. (2001). Orientação à queixa escolar. Psicologia em Estudo, 6(2), 129-134. https://doi.org/10.1590/S1413-73722001000200018

Furigo, R. C. P. L., Sanpedro, K. M., Zanelato, L. S., Foloni, R. F., Ballalai, R. C., \& Ormrod, T. (2008). Plantão psicológico: Uma prática que se consolida. Boletim de Psicologia, 58(129), 185-192.

Gomes, F. M.D. (2012). Plantão psicológico:Atendimentos em situações de crise. Vínculo-Revista do NESME 9(2), 1-50.

Gomes, M.A. F., \& Dimenstein, M. (2016). Serviço escola de psicologia e as políticas de saúde e de assistência social. Temas em Psicologia, 24(4), 1217-1231. http://dx.doi.org/10.9788/TP2016.4-03Pt 
Gonçalves, L. O., Farinha, M. G., \& Goto, T. A. (2016). Plantão psicológico em uma unidade básica de saúde: Atendimento em abordagem humanista-fenomenológica. Revista da Abordagem Géstáltica - Phenomenological Studies, XXII(2), 225-232.

Guerrelhas, F. F., \& Silvares, E. F. M. (2000). Grupos de espera recreativos: Proposta para diminuir o índice de evasão em clínica-escola de psicologia. Temas em Psicologia, 8(3), 313-321.

Herzberg, E., \& Chammas, D. (2009). Triagem estendida: Serviço oferecido por uma clínica-escola de psicologia. Paideia, 19(2), 107-114.

Holanda,A.(2006).Questõessobrepesquisaqualitativaepesquisafenomenológica.AnálisePsicológica,24(3),363-372.

Jovchelovitch, S., \& Bauer, M. W. (2001). Entrevista narrativa. In M. W. Bauer, \& G. Gaskell (Orgs.), Pesquisa qualitativa com texto, imagem e som: Um manual prático (pp. 90-113). Vozes.

Krug, J. S., \& Boeckel, M. G. (2016). Serviço-escola e as Diretrizes Curriculares Nacionais para formação em psicologia: Relato de uma experiência. In J. S. Krug, L. E. Prati, \& M. G. Boeckel (Orgs.), Fundamentos e práticas em serviço-escola: Espaço potencial de formação em psicologia (pp. 11-25). Juruá.

Krug, J. S., Boeckel, M. G., \& Andrade, R. (2016). Entrevista de triagem: O primeiro encontro no serviço-escola. In J. S. Krug, L. E. Prati, \& M. G. Boeckel (Orgs.), Fundamentos e práticas em serviço-escola: Espaço potencial de formação em psicologia (pp. 85-98). Juruá.

Kuczynski, E. (2014). Suicídio na infância e adolescência. Psicologia USP, 25(3), 246-252. http://dx.doi.org/ 10.1590/0103-6564D20140005

Laville, C., \& Dionne, J. (1999). A construção do saber: Manual de metodologia da pesquisa em ciências humanas. Artmed.

Löhr, S. S., \& Silvares, E. F. M. (2006). Clínica-escola: Integração da formação acadêmica com as necessidades da comunidade. In E. F. M. Silvares, Atendimento psicológico em clínicas-escola (pp. 11-22). Alínea.

Macêdo, S. (2015). Clínica humanista-fenomenológica do trabalho: A construção de uma ação diferenciada diante do sofrimento no e por causa do trabalho. Juruá.

Macêdo, S., \& Caldas, M. T. (2013). Merleau-Ponty e Gadamer: Possibilidade de se pesquisar a prática de psicólogos clínicos. In C. L. B. T. Barreto, H. T. P. Morato, \& M. T. Caldas (Orgs.), Prática psicológica na perspectiva fenomenológica (pp. 183-201). Juruá.

Mahfoud, M. (2004). Plantão psicológico: Novos horizontes. Companhia Ilimitada.

Mazer, S. M, \& Melo-Silva, L. L. (2010). Identidade profissional do psicólogo: Uma revisão da produção científica no Brasil. Psicologia: Ciência e Profissão, 30(2), 276-295. https://doi.org/10.1590/S1414-98932010000200005.

Melo-Silva, L. L., Santos, M. A., \& Simon, C. P. (2005). Serviço-escola em psicologia: A construção do saber prático. In L. L. Melo-Silva, M. A. Santos, \& C. P. Simon, Formação em psicologia: Serviços-escola em debate (pp. 21-30). Vetor.

Mesquita, A. C., \& Carvalho, E. C. (2014). A escuta terapêutica como estratégia de intervenção em saúde: Uma revisão integrativa. Revista da Escola de Enfermagem USP, 48 (6), 1127-36.

Nery, M. P., \& Costa, L. F. (2008). A pesquisa em psicologia clínica: Do indivíduo ao grupo. Estudos de Psicologia (Campinas), 25(2), 241-250. https://doi.org/10.1590/S0103-166X2008000200009

Nunes, A. P., \& Morato, H. T. P. (2020). O estágio de atendimento nos anos iniciais: Experiência com plantão psicológico. Revista da Abordagem Gestáltica, 26(1), 2-12. https://dx.doi.org/10.18065/RAG.2020v26n1.1

Oliveira-Monteiro, N. R., \& Nunes, M. L. T. (2008). Supervisor de psicologia clínica: Um professor idealizado? PsicoUSF, 13(2), 287-296.

Paparelli, R. B., \& Nogueira-Martins, M. C. F. (2007). Psicólogos em formação: Vivências e demandas em plantão psicológico. Psicologia: Ciência e Profissão, 27(1), 64-79. https://doi.org/10.1590/S1414-98932007000100006

Resolução nº 5, de 15 de março de 2011. Brasil, Conselho Nacional de Educação, Câmara de Educação Superior (2011). http://portal.mec.gov.br/index.php?option=com_docman\&view=download\&alias=7692-rces005-11-pdf\&Itemid=30192

Resolução no 466, de 12 de dezembro de 2012. Brasil, Conselho Nacional de Educação (2012). https:/ / bvsms.saude. gov.br/bvs/saudelegis/cns/2013/res0466_12_12_2012.html 
Ribeiro, L. T. F., \& Araújo, O. H. A (2017). O estágio supervisionado: Fios, desafios, movimentos e possibilidades de formação. RIAEE - Revista Ibero-Americana de Estudos em Educação, 12(3), 1721-1735.

Rocha, M. C. (2011). Plantão psicológico e triagem: Aproximações e distanciamentos. Revista do Nufen, 3(1), $119-134$.

Romagnoli, R. C., Amorim, A. K. M. A., Severo, A. K. S. S., \& Nobre, M. T. (2017). Intersetorialidade em saúde mental: Tensões e desafios em cidades do Sudeste e nordeste brasileiro. Revista Subjetividades, 17(3), $157-168$. https://doi.org/10.5020/23590777.rs.v17i3.6075

Rosenthal, R. W. (1999). O plantão psicológico no Instituto Sedes Sapientiae: Uma proposta de atendimento aberto à comunidade. In M. Mahfoud (Org.), Plantão psicológico: Novos horizontes (pp. 15-28). Companhia Ilimitada.

Sá, R. N., Azevedo, O., Jr., \& Leite, T. L. (2010). Reflexões fenomenológicas sobre a experiência de estágio e supervisão clínica em um serviço de psicologia aplicada universitário. Revista da Abordagem Gestáltica, XVI(2), 135 -140.

Santos, A. C., \& Nóbrega, D. O. (2017). Dores e delícias em ser estagiária: O estágio na formação em psicologia. Psicologia: Ciência e Profissão, 37(2), 515-528. http://dx.doi.org/10.1590/1982-3703002992015

Schmidt, M. L. S. (2004). Plantão psicológico, universidade pública e política de saúde mental. Estudos de Psicologia Campinas, 21(3), 173-192.

Sousa, D. (2017). Investigação científica em psicoterapia e prática psicoterapêutica: Os dados da investigação mais relevantes para os clínicos. Fim de Século.

Souza, E. L. C., Barros Neta, F. T., \&Vieira, E. M. (2012). Interface do plantão psicológico e as políticas de assistência social. Revista do NUFEN, 4(2), 71-82.

Teixeira, D. C., \& Vorcaro, A. R. (2009). Acolhimento em clínica-escola: O tratamento a queixa. Revista Saúde e Pesquisa, 2(2), 281-286.

Turato, E. R. (2003). Tratado de metodologia da pesquisa clínico-qualitativa. Vozes.

Velasco, K., Rivas, L. A. F., \& Guazina, F. M. N. (2012). Acolhimento e escuta como prática de trabalho do psicólogo no contexto hospitalar. Disciplinarum Scientia, 13(2), 243-255. https://doi.org/10.37780/ch.v13i2.1741

Yehia, G. Y. (2004). Interlocuções entre o plantão psicológico e o psicodiagnóstico colaborativo. Estudos de Psicologia (Campinas), 21(1), 65-72. https://doi.org/10.1590/S0103-166X2004000100006

\section{Shirley Macêdo}

Doutora em Psicologia Clínica, docente do Colegiado de Psicologia da Residência em Saúde Mental da Universidade Federal do Vale do São Francisco, Petrolina - PE. Brasil.

E-mail: mvm.shirley@gmail.com

(D) https:// orcid.org/0000-0003-1619-2353

\section{Ana Lícia Pessoa Nunes}

Graduada em Psicologia pela Universidade Federal do Vale do São Francisco, Petrolina - PE. Brasil.

E-mail: analicia.pessoa@hotmail.com

(D) https://orcid.org/0000-0002-1107-8431

\section{Milena Vitor Gama Duarte}

Graduada em Psicologia pela Universidade Federal do Vale do São Francisco, Petrolina - PE. Brasil.

E-mail: milenavgduarte@gmail.com

(D) https://orcid.org/0000-0003-2476-194X

\section{Agradecimentos}

Ao Programa de Iniciação Científica do Conselho Nacional de Desenvolvimento Científico e Tecnológico (CNPq) e à Universidade Federal do Vale do São Francisco (Univasf). 
Endereço para envio de correspondência:

Av. José de Sá Maniçoba, s/n. CEP: 56304-205. Petrolina- PE. Brasil.

Recebido 08/02/2019

Aceito 14/08/2020

Received 02/08/2019

Approved 08/14/2020

Recibido 08/02/2019

Aceptado 14/08/2020

Como citar: Macêdo, S., Nunes, A. L. P., \& Duarte, M. V. G. (2021). Escuta Clínica, Triagem e Plantão Psicológico em um Serviço-Escola Pernambucano. Psicologia: Ciência e Profissão, 41, 1-17.

https://doi.org/10.1590/1982-3703003219706

How to cite: Macêdo, S., Nunes, A. L. P., \& Duarte, M. V. G. (2021). Clinical Listening, Screening and Psychological Support on a School Clinic in Pernambuco. Psicologia: Ciência e Profissão, 41, 1-17.

https://doi.org/10.1590/1982-3703003219706

Cómo citar: Macêdo, S., Nunes, A. L. P., \& Duarte, M. V. G. (2021). Escucha clínica en clasificación y turno psicológico en un servicio escuela pernambucano. Psicologia: Ciência e Profissão, 41, 1-17.

https://doi.org/10.1590/1982-3703003219706 